\title{
Effect of triclosan containing-dentifrice on subgingival microbiota in children from generalized aggressive periodontitis parents.
}

\section{Gabriela M. Bonilha*, Mabelle F. Monteiro, Aurélio A. Reis, Renato C. Casarin.}

\begin{abstract}
Generalized aggressive periodontitis (GAgP) cause a rapid and severe destruction periodontal tissues and it is characterized by an altered microbiological profile and familial aggregation. Studies involving children from GAgP individuals identified early clinical and microbiological changes in these individuals, suggesting that this aspect could be related to disease susceptibility. The aim of this study was to evaluate the effect of Triclosan toothpaste in the concentration of periodontopathogens present in the subgingival biofilm in children from GAgP parents, compared to children from periodontally health parents. Subgingival biofilm were collected from incisors and first molars. The bacterial DNA were extracted and the total amounts of $A$. actinomycetemcomitans (Aa), Fusobacterium nucleatum, $P$. gingivalis and $\mathrm{T}$. forsythia were evaluated by $\mathrm{qPCR}$. At baseline, children from GAgP parents presented higher plaque index $(\mathrm{PI})$, gingival index (GI), and bleeding on probing (BoP) as well as higher concentration of Aa subgingivally. The PI was controlled by both toothpastes. Triclosan Toothpaste reduced the Gl for both groups and aditional reduction in PD ana BoP were demontrated in the GAgP group. No effect of triclosan tothpaste was observed in pathogens concentration. In conclusion, Triclosan toothpaste was more effective than placebo toothpaste to control the clinical condition in children from GAgP parents, however both treatments did not change the microbiological condition.
\end{abstract}

\section{Key words: Triclosan, agressive periodontitis, subgengival microbiology.}

\section{Introduction}

- GAgP is a multifactorial disease characterized by the familial aggregation of cases ${ }^{1}$;

- Previous studies have demonstrated alterations on the clinical conditions and microbial profile on children from GAgP parents, situation that can be related to risk and susceptibility to disease ${ }^{2}$;

- The use of antimicrobial associated to plaque control could be an interesting approach to control the precocious alterations observed on that population ${ }^{3}$;

- Triclosan toothpaste has antimicrobial properties, it is commercially available, and it has an easy-to-use and secure form of application;

- This study aimed to evaluate the use of Triclosan toothpaste to control the clinical and microbiological condition in children from GAgP parents, compared to children from periodontally health parents, in a cross-over placebo-controlled clinical trial.

\section{Results and Discussion}

Table 1 Demographic, clinical and microbiological condition at baseline in children from Health and GAgP groups.

\begin{tabular}{cccc}
\hline & GAgP $(\mathbf{n}=15)$ & Health $(\mathbf{n = 1 5})$ \\
\hline Gender $(\%$ fem) & $60 \%$ & $40 \%$ \\
Age (years \pm SD) & $9.2 \pm 1.7$ & $9.0 \pm 2.0$ \\
PI $(\% \pm S D)$ & $36.2 \pm 14.7$ \& & $25.1 \pm 13.1$ \\
GI $(\% \pm S D)$ & $10.4 \pm 4.7 \&$ & $7.5 \pm 5.3$ \\
& PD $(\mathrm{mm} \pm$ SD) & $1.7 \pm 0.4$ & $1.6 \pm 0.6$ \\
& BoP $(\% \pm S D)$ & $25.3 \pm 7.0^{*}$ & $17.9 \pm 11.4$ \\
Subgingival & A.actinomycetemcomitans & $2.6 \pm 2.0^{*}$ & $1.7 \pm 1.7$ \\
biofilm & P. gingivalis & $1.1 \pm 1.7$ & $0.3 \pm 1.1$ \\
(log10 [ ] \pm SD) & T. forsythia & $0.1 \pm 0.5$ & $0 \pm 0$
\end{tabular}

Symbols indicate statistical difference between groups $\left({ }^{\&} \mathrm{~T}\right.$-Student test and *MannWhitney test, $\mathrm{p}<0.05)$. PI - Plaque Index; GI - Gingival Index; PD -Probing Depth BoP - Bleeding on probing; SD - Standard deviation;

Table 2 Clinical data of baseline and 45 days after the use of Triclosan and Placebo toothpaste per group.

\begin{tabular}{|c|c|c|c|c|c|c|}
\hline & & & PI $(\% \pm S D)$ & GI $(\% \pm S D)$ & $\mathrm{PD}(\mathrm{mm} \pm \mathrm{SD})$ & $\mathrm{BoP}(\% \pm S D)$ \\
\hline \multirow{4}{*}{ GAgP } & \multirow{2}{*}{ Triclosan } & Baseline & $30.8 \pm 15.8$ & $9.6 \pm 5.2$ & $1.8 \pm 0.3$ & $26.4 \pm 11.4$ \\
\hline & & 45 days & $24.7 \pm 12.0^{*}$ & $7.1 \pm 4.1^{*}$ & $1.5 \pm 0.4^{\#}$ & $22.8 \pm 8.9 *$ \\
\hline & \multirow{2}{*}{ Placebo } & Baseline & $34.1 \pm 17.0$ & $10.6 \pm 5.6$ & $1.7 \pm 0.4$ & $24.2 \pm 12.5$ \\
\hline & & 45 days & $27.7 \pm 11.1^{*}$ & $10.4 \pm 8.1$ & $1.6 \pm 0.6$ & $25.5 \pm 10.9$ \\
\hline \multirow{4}{*}{ Health } & \multirow{2}{*}{ Triclosan } & Baseline & $26.5 \pm 14.2$ & $8.4 \pm 5.2$ & $1.6 \pm 0.6$ & $17.6 \pm 13.4$ \\
\hline & & 45 days & $20.1 \pm 13.4^{*}$ & $5.3 \pm 4.4^{*}$ & $1.6 \pm 0.6$ & $17.5 \pm 9.5$ \\
\hline & \multirow{2}{*}{ Placebo } & Baseline & $26.0 \pm 12.9$ & $6.5 \pm 5.8$ & $1.6 \pm 0.6$ & $18.6 \pm 10.2$ \\
\hline & & 45 days & $22.1 \pm 11.7^{*}$ & $6.6 \pm 5.3$ & $1.3 \pm 0.8$ & $19.1 \pm 15.3$ \\
\hline
\end{tabular}

Symbols indicate statistical difference intragroup per treatment ("ANOVA two-way ttest and *Wilcoxon test, $\mathrm{p}<0.05)$. PI - Plaque Index; GI - Gingival Index; PD - Probing Depth; BoP - Bleeding on probing; SD - Standard deviation;

Figure 1 Effect of plaque control using placebo and triclosan toothpaste in the bacterial concentration in subgingival biofilm.

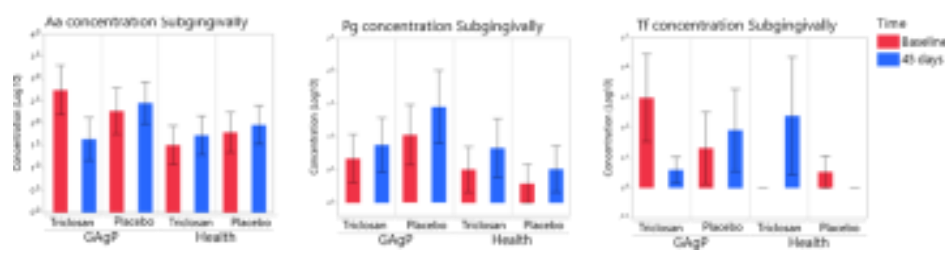

In conclusion, the triclosan toothpaste demonstrated to be more efficient than placebo toothpaste to control the clinical condition in children from GAgP parents, despite no microbiological benefits.

\section{Acknowledgement}

$\mathrm{PIBIC/} \mathrm{CNPq}$ for the grant of scientific initiation.

\footnotetext{
${ }^{1}$ Armitage GC. Development of a classification system for periodontal diseases and conditions. Ann Periodontol. 1999 Dec;4(1):1-6.

2 Monteiro M, Casati MZ, Taiete T, et al (2015) Periodontal clinical and microbiological characteristics in healthy versus generalized aggressive periodontitis families. J Clin Periodontol 42:914-921.

${ }^{3}$ Riley P, Lamont T (2013) Triclosan/copolymer containing toothpastes for oral health (Review) Triclosan/copolymer containing toothpastes for oral health. 12
} 15 . 